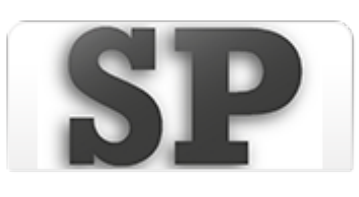

Sociedades precapitalistas ISSN: 2250-5121

publicaciones@fahce.unlp.edu.ar

Universidad Nacional de La Plata

Argentina

\title{
Esencia y apariencia de las relaciones sociales: colonos y propietarios en el imperio romano
}

\author{
Perelman Fajardo, Marcelo Emiliano \\ Esencia y apariencia de las relaciones sociales: colonos y propietarios en el imperio romano \\ Sociedades precapitalistas, núm. 10, 2020 \\ Universidad Nacional de La Plata, Argentina \\ DOI: https://doi.org/10.24215/22505121e044
}

Atribución no comercial compartir igual (CC BY-NC-SA) 4.0 
Dossier: Formas de explotación del trabajo y relaciones laborales en sociedades preindustriales

\section{Esencia y apariencia de las relaciones sociales: colonos y propietarios en el imperio} romano

Essence and appearance of social relationships: tenants and landowners in the Roman Empire

Marcelo Emiliano Perelman Fajardo

DOI: https://doi.org/10.24215/22505121e044

Universidad de Buenos Aires, Argentina

mperelman88@hotmail.com

Recepción: 11 Mayo 2019

Aprobación: 17 Julio 2019

Recepción: 11 Mayo 2019

Aprobación: 17 Julio 2019

\section{Resumen:}

La historiografía ha analizado tradicionalmente el problema del arrendamiento de tierras en la Antigua Roma desde una perspectiva formalista, caracterizando el lazo social entre el colono y el propietario únicamente desde el punto de vista contractual, como dos sujetos autónomos que establecen una relación de manera voluntaria y libre. Pero la estrechez de tal enfoque, derivado principalmente de la gran importancia que tuvo el desarrollo del derecho en Roma, no resulta suficiente a la hora de explicar diferentes fenómenos que se pueden apreciar en las fuentes, donde también se observan rasgos de dependencia "personal" en la relación entre arrendatarios y propietarios. $\mathrm{Al}$ analizar estos aspectos, veremos que no suponen la inexistencia del interés económico en este tipo de relaciones, sino que su razón de ser es precisamente la de ocultar este interés para su efectiva realización. Se trata de formas aparenciales, aunque necesarias, que el interés económico adquiere en las sociedades precapitalistas, y que éstas se ufanan por ocultar.

Palabras Clave: Imperio romano, Colonos, Propietarios, Relación personal.

\section{Abstract:}

The historiography has traditionally analyzed the problem of land tenure in Ancient Rome from a formalist perspective, characterizing the social bond between the tenant and the owner only from the contractual point of view, as two autonomous subjects who establish a relationship voluntarily and free. But the narrowness of this approach, derived mainly from the great importance of the development of law in Rome, is not enough when we have to explain different phenomena that can be seen in the sources, where we can see too certain features of 'personal' dependence of the relationship between tenants and owners. In the analysis of these aspects, we will see that they do not imply the inexistence of economic interest in this type of relationship, but rather its reason for being is to hide this interest for its effective realization. It is about appearances, although necessary, acquired by the economic interest in pre-capitalist societies, and that these boast to hide.

KEYWORDS: Roman Empire, Tenants, Landowners, Personal relationship.

\section{INTRODUCCIÓN}

La historiografía ha analizado tradicionalmente el problema del arrendamiento de tierras en la Antigua Roma desde una perspectiva formalista, caracterizando el lazo social entre el colono y el propietario únicamente desde el punto de vista contractual, como dos sujetos autónomos que establecen una relación de manera voluntaria y libre. La estrechez de tal enfoque, derivado principalmente de la gran importancia que tuvo el desarrollo del derecho en Roma, no resulta suficiente a la hora de explicar diferentes fenómenos que se pueden apreciar en otro tipo de testimonios. Tanto en las fuentes literarias como en los tratados agronómicos apreciamos la existencia de relaciones de intercambio de dones y contradones en donde la cesión de la tierra por parte del terrateniente supone distintas contraprestaciones por parte del colono, que incluyen no solo el pago de una renta sino también la obligación de realizar servicios laborales, militares e incluso pequeñas "atenciones", como regalos o saludos. En base a fuentes usualmente dejadas de lado por la historiografía 
del tema, como es el caso de algunos poemas, epigramas y cartas que caracterizan el comportamiento de los actores rurales, como así también en la consideración de una lectura alternativa de fuentes canónicas de la literatura económica latina, como es el caso de Catón y Columela, procuraremos alumbrar ciertos rasgos de dependencia "personal" de la relación entre arrendatarios y propietarios. A su vez, podremos observar que estos aspectos no suponen la inexistencia del interés económico en este tipo de relaciones, sino que su razón de ser es precisamente la de ocultar este interés para su efectiva realización. Se trata de formas aparenciales, aunque necesarias, que el interés económico adquiere en las sociedades precapitalistas, y que éstas se ufanan por ocultar.

\section{La imagen del propietario en Nemesiano y Plinio el Joven}

El poeta latino Nemesiano, africano del siglo III d. C., habría de dejarnos uno de los retratos más elocuentes acerca de las virtudes modélicas de un propietario rural. En su Bucólica I, el pastor Timetas entona un epicedio en honor del difunto Melibeo, caracterizándolo de la siguiente manera (vv. 49-57):

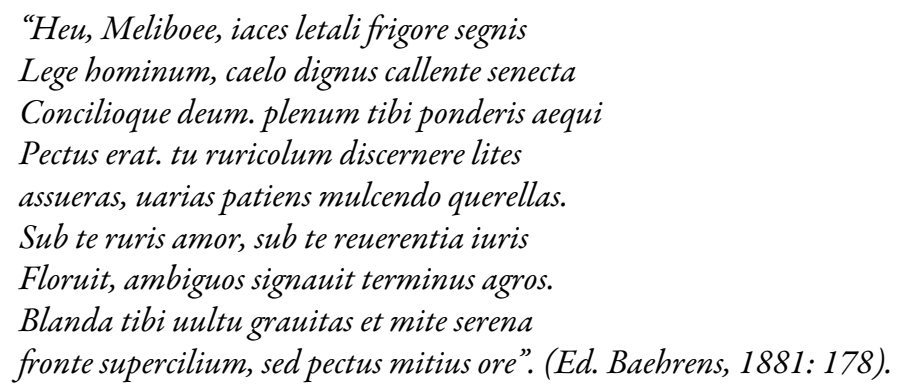

Según Timetas, Melibeo tiene un “corazón lleno de una justicia ponderada” (plenum ponderis aequipectus): resuelve conflictos entre campesinos (ruricolum lites) y aplaca apaciblemente (pacans ${ }^{I}$ mulcendo) sus lamentos (querellas). La auctoritas de Melibeo hace florecer la actividad agrícola, esto es, el "amor al campo" (ruris amor); también impera el respeto al derecho (reuerentia iuris) y se trazan con claridad los límites de los campos (ambiguos signauit terminus agros). Una "encantadora gravidez" (blanda grauitas) se desprende del rostro de Melibeo, de "frente serena" (serena fronte) y de "cejas tiernas" (mite supercilium), pero es "más tierno aún su corazón que su rostro" (sed pectus mitius ore). Hay aquí ciertamente una combinación de virtudes antitéticas: de rigor para hacer cumplir la ley, pero también de calidez para calmar y sosegar a los ofendidos. Con ellas, este caudillo rural asegura la paz en el vecindario y la correcta realización de las tareas agrícolas.

Por su contenido, esta égloga fue generalmente comprendida como una muestra del feudalismo incipiente tras la crisis del siglo III (Schtajerman, 1964: 42; Kolendo, 1976: 65). La idea de un gran propietario que, ante la decadencia de los poderes públicos, se erige como juez de su comarca, resolviendo pleitos de los campesinos bajo su protección, calzaba bien con la noción del señor feudal prototípico. Lo cierto es que esta figura no era ajena para romanos de épocas anteriores. Encontramos varios rasgos del Melibeo de Nemesiano en otros escritores interesados en presentarse a sí mismos como dechados de esas virtudes, como síntesis de la gravitas y de la comitas. Plinio el Joven es un claro ejemplo de esta actitud aristocrática, dejando constancia en numerosas cartas del pesar que le ocasionaba atender los problemas de sus campesinos. En una de sus cartas más elocuentes, deja en claro este rol de "juez popular", desempeñado en sus propiedades rurales (VII.30.2-3): "Me huc quoque urbana negotia persecuntur. Non desunt enim qui me iudicem aut arbitrum faciant. Accedunt querellae rusticorum, qui auribus meis post longum tempus suo iure abutuntur" (Ed. Keil, 1886: 151). No solo en la ciudad, sino también en sus posesiones rurales Plinio debía actuar como juez o árbitro (iudicem aut arbitrum), a lo que se agregaba el prestar oídos a las quejas de los campesinos (querellae rusticorum). Como se ve, expresiones muy similares a las que encontrábamos en Nemesiano. El 
tono patético de Plinio para lamentarse de las fatigosas demandas de las que era objeto buscaba ciertamente hacer ver su importancia como patrón local, ilustrando a su vez la forma en la que un aristócrata veía su lugar como propietario y su relación con el vecindario rural. A despecho de la actividad literaria, su vocación más añorada, Plinio debía atender sus obligaciones como administrador de sus tierras, una actividad que describe como agobiante (V.14.8): "circumibam agellos, audiebam multum rusticarum querellarum, rationes legebam invitus et cursim (aliis enim chartis, aliis sum litteris initiatus)" (Ed. Keil, 1886: 103). Escrita desde Como, su ciudad natal, esta carta nos muestra a Plinio en la obligación de atender no solo a familiares y amigos, como afirmaba con anterioridad, sino también de encargarse de las tareas de administración de sus "campitos" (agellos), en las que se incluían el "repaso de las cuentas" (rationes legebam), una tarea por la que profesaba poco interés ya que otras eran las "letras" (litteris) que le interesaban, y la atención de las "quejas de los campesinos" (rusticarum querellarum). En otra carta, esta vez en su propiedad de la Toscana, nuevamente describe Plinio el agobio que siente al tener que dedicarse a asuntos administrativos (IX.15.1-3):

"Refugeram in Tuscos, ut omnia ad arbitrium meum facerem; ad hoc ne in Tuscis quidem: tam multis undique rusticorum libellis et tam querulis inquietor, quos aliquanto magis invitus quam meos lego; nam et meos invitus. (...) Rationes quasi absente me negleguntur. Interdum tamen equum conscendo et patrem familiae hactenus ago, quod aliquam partem praediorum, sed pro gestatione percurro. (Ed. Keil, 1886: 183)"

Acosado por las escritos y las quejas de los campesinos (rusticorum libellis et querulis) y con las cuentas en estado de abandono (rationes negleguntur), apenas se digna Plinio a "hacer de pater familias" (patrem familiae hactenus ago) montando a caballo y dando una vuelta por sus predios. Quienes más demandaban su atención solían ser los arrendatarios a su servicio, cuyos reclamos abrumaban a nuestro autor (IX.36): "Datur et colonis, ut videtur ipsis, non satis temporis, quorum mihi agrestes querellae litteras nostras et haec urbana opera commendant" (Ed. Keil, 1886: 196). La mención a coloni en esta carta marca con mayor precisión el estatus de aquellos rustici quejosos de las epístolas anteriores. Sabemos por otras cartas muy analizadas por la historiografía económica, III.19 y IX.37, que el mayor problema que afrontaban los colonos de Plinio eran los atrasos en el pago de la renta, lo que ocasionaba una situación de endeudamiento desesperante. Dentro de los múltiples casos que un propietario debía atender en su finca, los problemas de producción de los colonos debían de ser el contenido principal de aquellas "quejas rústicas". Además de los colonos, la clientela rural podía demandar los servicios de Plinio, ya que probablemente también fuera arrendataria de parte de sus tierras. Resultaba lógico en este sentido que un personaje prominente del vecindario captara la atención de la población local durante su estadía.

La imagen del propietario romano que emerge de los textos de Nemesiano y Plinio se asemeja bastante a lo que Marx denominó como la relación "aristocrática” de la propiedad de la tierra (Marx, 2004: 99). Ésta se caracterizaba por tener la "apariencia" de una relación más íntima entre el propietario y la tierra que la de la mera riqueza “objetiva”. El propietario no se molestaba en extraer el máximo beneficio de sus posesiones, sino que delegaba las preocupaciones productivas en sus arrendatarios. A su vez, éstos tampoco se relacionaban con la tierra como simples "jornaleros", sino que entablaban con ella una relación de "respeto, sumisión y deber". La tierra, en definitiva, no era un simple objeto inerme, sino que tenía un costado "acogedor". Es cierto que Marx se refería principalmente al feudalismo, aunque precisamente a Nemesiano y a Plinio se los consideró como precedentes de este modo de producción. El problema es que tal vez la historiografía de la antigüedad haya hecho demasiado hincapié en el predominio excluyente de relaciones contractuales entre colonos y propietarios para épocas más tempranas, obviando determinados aspectos "personales" o "extra-económicos" que esta relación solía conllevar. Si en la figura del propietario se conjugaban diferentes demandas sociales de parte de las clases subalternas, estas evidencias nos sugieren la existencia de un rol paternalista del terrateniente sobre el campesinado, que debía de vivir en los alrededores de la explotación y que dependían crucialmente de ella para su subsistencia, ya sea arrendando algunas parcelas, trabajando como jornaleros en algunos momentos del año para el gran propietario, o incluso ambas. Sin embargo, no debe olvidarse que, según Marx, se trata en realidad de una "apariencia", cuestión que luego retomaremos. 


\section{La descripción de la finca de Faustino por el poeta Marcial (Ep.III.58)}

Otra sugerente fuente sobre estas cuestiones es un poema de Marcial, escritor del siglo I d. C. Se trata del epigrama III.58, un elogio de una finca de Faustino, un amigo del poeta e importante propietario de tierras en Anxur, Tibur y Bayas. Su singularidad viene dada por la mención de varias figuras asociadas al escenario rural romano: esclavos, capataces, campesinos, colonos, vecinos, etc. Se ha dicho que este epigrama era más una descripción idílica que una representación fidedigna de una típica villa (Scheidel, 1994: 64). Consideramos que esta visión echa de menos la posibilidad de apreciar las formas en las cuales la elite solía imaginarse el óptimo desenvolvimiento de la relación con el vecindario rural. De esta forma podremos ver algunos indicios acerca de qué tipo de actitudes esperaban las clases propietarias romanas de sus subordinados sociales, y viceversa.

Como señalábamos, el epigrama elogia la finca de Faustino en Bayas, en la costa de la Campania. Sus virtudes son contrapuestas a las de aquellas que no producen nada por sí mismas y deben comprar todo en el mercado de la ciudad, como es el caso de la finca de Baso, descrita en el epigrama III.47. El epigrama III.58 se dirige precisamente a este Baso, como lección acerca de la forma en la cual debe explotarse una finca. Luego de una larga descripción sobre la riqueza y abundancia de la villa, poblada de numerosos y laboriosos esclavos, hacen su aparición amigables campesinos que vienen a saludar con regalos (33-38): "Nec venit inanis rusticus salutator: / fert ille ceris cana cum suis mella / metamque lactis Sassinatis; e silva / somniculosos ille porrigit glires; / hic vagientem matris hispidae fetum, / alius coactos non amare capones" (Ed. Friedlander, 1886: 311-12). Podemos suponer que la presentación de obsequios fuera algo bastante generalizado, como forma de reconocimiento al propietario por su influencia sobre la comunidad. Se destacan en la enumeración de Marcial productos derivados de la ganadería o de la caza: miel (cana mella), queso (lactis Sassinatis), lirones (glires, tipo de roedor usado como mascota) y gallos castrados (capones), muy apetecibles éstos por su sabrosa carne. Jerzy Kolendo (1976: 60-1) notó que la propia forma "física" de este tipo de presentes nos daba de por sí un indicio de que estamos frente a una relación de subordinación, basando esta observación en el clásico estudio de Marcel Mauss (2012) sobre el intercambio de dones en las sociedades primitivas. Que estos intercambios eran importantes y debían respetarse nos lo dice la alusión a que el campesino no venga "inane". Respecto a la posible identidad de algunos de estos rustici, tenemos un indicio en los siguientes versos (39-40): "Et dona matrum vimine offerunt texto / grandes proborum virgines colonorum" (Ed. Friedlander, 1886: 312). Aquí tenemos una precisión mayor que la del genérico "campesino". Un colono que explotara tierras a cambio de una renta, también debía presentar sus respetos al dueño de la parcela bajo la forma de regalos. Que por “colonos” Marcial no esté aludiendo a campesinos sino a pequeños arrendatarios es algo que se puede deducir del calificativo "honrados" (proborum). ${ }^{2}$ La cesión temporal de una parcela debía de suponer una aceitada relación de confianza ente ambas partes. En este idilio rural resulta lógico pensar que el colono ideal fuese alguien "honrado" o "probo", en el sentido de que trabaje por sí mismo la tierra (algo que, por ejemplo, no hacía el colono "urbano" contra el cual advertía Columela, RR.I.7.3) y que no buscara engañar al propietario a la hora de realizar los pagos (un peligro que Plinio el Joven evitaba poniendo esclavos, custodes, a vigilar la cosecha de los colonos, Ep.IX.37).

Pero aunque el arrendamiento fuera considerado una relación contractual por los juristas romanos, este tipo de atenciones nunca son mencionadas en las disposiciones jurídicas que regulaban la locatio conductio: si nos atenemos a la clásica definición de Gayo (Dig.XIX.2.25), la locación caía bajo los mismos términos que los de la compra y venta, pues se consideraba que se vendía el usufructo temporal de la cosa, siendo equivalentes el precio del alquiler (merces) al precio (pretio) de una mercancía vendida. Podría decirse que, si la venta de un objeto supone la separación definitiva del que vende respecto de lo vendido, difícilmente se aplicara esto al arrendamiento, ya que el propietario seguía de cerca el usufructo que su colono hacía de su tierra, como queda atestiguado en el testimonio de Columela que más adelante veremos. El caso es que, como ningún jurista hacía mención a regalos, la solución fácil de la historiografía fue o negar que estos 
colonos fueran arrendatarios, o directamente ignorar este tipo de evidencias. Walter Scheidel (1994: 64), quien en su tesis sobre el arrendamiento en Roma buscó explicar todas las referencias a colonos habidas en las fuentes como alusiones a grandes arrendatarios farmers, apeló a la continuación del epigrama para sostener que el fragmento no aludía a colonos arrendatarios (41-44): "Facto vocatur laetus opere vicinus; / nec avara servat crastinas dapes mensa, / vescuntur omnes ebrioque non novit / satur minister invidere convivae" (Ed. Friedlander, 1886: 312). Scheidel argumenta que la mención de vicinus explicaría el sentido de colonorum, no como arrendatarios, sino como simples vecinos de la villa, sin necesidad de ver a estos salutatores como campesinos dependientes.

Otros historiadores tuvieron una apreciación más compleja del fenómeno. Uno de ellos fue KlausPeter Johne (1983: 123), quien señaló que los colonos de Marcial no eran solo meros arrendatarios, sino que también podían caer bajo la rótula de la clientela, siendo una especie de colonos/clientes. Que la superposición de estas dos figuras debía ser algo bastante común lo indica el hecho de que a menudo los propios escritores romanos confundieran ambos términos o los tomaran casi como sinónimos, aspecto advertido tempranamente por Christoph Schultz (1833: 341). Podemos deducir entonces que el alquiler de la tierra debía suponer toda una relación anterior caracterizada por una serie de obligaciones recíprocas compatible con la relación clientelar. Los dones que los colonos llevaban a la finca de Faustino representaban tanto la subordinación social en la que se encontraban como también el intento por forjar lazos de obligación sobre el propietario, para que así pudieran ocasionalmente recibir su ayuda en un momento de urgencia. A su vez, el propietario, al desplegar su protección sobre el vecindario, podía asegurarse múltiples beneficios, desde la formación de un ejército rural, algo bastante común en la época de las guerras civiles de finales de la república, como también el reclutamiento de mano de obra para los trabajos agrícolas de su finca (Brunt, 1962: 71-72). Por supuesto, nada de esto debía hacerse de forma descarada y abierta, sino que era necesario un cierto grado de opacidad, una apariencia de desinterés y generosidad, pues en estas sociedades "la única justificación del poder es el desinterés" (Sahlins, 1977: 152).

Quien fuese vecino de un propietario opulento e influyente es probable que se encontrara bajo algún tipo de subordinación "protectora", relación que ambas partes buscaban entablar. El propio concepto de vicinus no es neutro, sino que alude de forma usual en las fuentes a una relación de dependencia (Schtajerman, 1964: 43). Si hay algo que resulta claro de este pasaje es que estamos en presencia de un intercambio de presentes que podía deberse, podemos especular, al agradecimiento de los campesinos de la zona al dueño por haberles otorgado el usufructo de alguna parcela, o también por algún otro servicio, sea de tipo judicial o económico, que el propietario hubiese realizado y del cual se hubieran beneficiado. Lo que es más revelador aún es que el propietario también debía mostrar cierta gratitud hacia ellos. El ablativo absoluto facto opere alude a una jornada laboral terminada, luego de la cual es invitado el "alegre vecino" (laetus vicinus). Esta expresión puede indicar que el colono/vecino podía ser "contratado" para realizar determinados trabajos específicos en la finca, siendo una de las retribuciones del señor el ofrecimiento de una comida una vez que el trabajo había finalizado. Un apoyo extra a esta interpretación es la alusión al "sirviente satisfecho" (satur minister) que no envidia al "invitado ebrio" (ebrio convivae), colocando a ese vecino invitado al nivel de un dependiente. Es muy probable que fuera una costumbre asentada el alimentar al trabajador, fuesen jornaleros o colonos, durante los días de trabajo (Weber, 1982: 177), algo que queda atestiguado por Columela, en RR.XI.1.14, donde se menciona a campesinos (rusticos) invitados a compartir la mesa del propietario, y también en RR.II.9.17, donde Columela recomienda qué cereales deben cultivarse para alimentar al personal de servicio (esclavos y colonos). Es de suponer que esto se diese principalmente durante la cosecha, como se desprende del verso 48 de Marcial: "et vinitorem farre pascis urbano" (Ed. Friedlander, 1886: 312). Se trata de una crítica a Baso, cuya villa no producía los alimentos necesarios para satisfacer las necesidades de sus trabajadores y por eso debía recurrir al mercado urbano. Se desprende de este pasaje también que las haciendas romanas no solo debían enfocarse en cultivos comercializables (viñedos) sino también del grano necesario para el consumo de la fuerza de trabajo (vinitorem). 


\section{Los Consejos de Columela y Catón}

Lo relatado en el epigrama de Marcial se asemeja a algunos pasajes de De rerustica de Columela, especialmente cuando se ocupa del óptimo desarrollo de las relaciones entre el propietario y sus colonos. En el capítulo 7 del primer libro, donde se aborda el tema de la fuerza de trabajo de la finca, así se refiere Columela a la relación con los colonos (1.7.1): "Comiter agat cum colonis, facilemque se praebeat et auarius opus exigat quam pensiones, quoniam et minus id offendit et tamen in uniuersum magis prodest" (Ed. Lündstrom, 1917: 36). En primer lugar, Columela le recomienda al propietario que trate amablemente (comiter) a los colonos y que se muestre afable (facilemque se praebeat) con ellos. Luego pasa de la cuestión de las formas al contenido de la relación, al aconsejar que se sea más exigente con los trabajos que con los pagos (auarius opus exigat quam pensiones). El significado último de esta afirmación ha generado ríos de tinta entre los historiadores, principalmente referido a la interpretación de opus. El debate giró en torno a traducir este término como servicios laborales, algo que traería inmediatas conexiones con el señorío feudal y la servidumbre, mientras que la postura mayoritaria de los historiadores fue considerar que Columela se refería al correcto cultivo de la parcela arrendada. No abordaremos aquí el significado estrictamente económico de esta aseveración de Columela. Lo que nos resulta llamativo es que el parámetro esencial, sine qua non, que los juristas romanos tomaron para definir el contrato de arrendamiento, esto es, el pago de una renta, resulte aquí un aspecto secundario para el interés del propietario. La justificación incluso es todavía más sorprendente que el consejo mismo: afirma que esto no solo es menos ofensivo (et minus id offendit) sino también en general más rentable (et tamen in uniuersum magis prodest). Es de recalcar que la principal cláusula de un contrato y su fundamento último, el pago de una renta, sea considerado para quien debe hacerlo, el colono, como algo "ofensivo". Al parecer, entre el pago de una renta y la realización de ciertos trabajos, Columela encontraría que pedir esto último ofendería menos.

A continuación Columela describe con algo de mayor exactitud las obligaciones del colono y el comportamiento que aconseja al propietario sobre esta cuestión (I.7.2): "Sed nec dominus in unaquaque re, cui colonum obligauerit, tenax esse iuris sui debet, sicut in diebus pecuniarum uel lignis et ceteris paruis accessionibus exigendis, quarum cura maiorem molestiam quam impensam rusticis adfert. Nec sane est uindicandum nobis quicquid licet, nam summum ius antiqui summam putabant crucem" (Ed. Lündstrom, 1917: 36-37). Si quisiéramos sintetizar los consejos de Columela acerca de la relación del patrón con su colono, podríamos apelar a ese proverbio jurídico que él cita al final: el cumplimiento extremo de la ley es la suma injusticia (summum ius, summa iniuria), coloquialmente expresado por Columela como summum ius summam crucem. ¿A qué se refiere con esto? A que el propietario no debe ejercer todos los derechos que posee sobre el colono, ya que esto constituiría un abuso: no debe ser riguroso (tenax) con aquellas cosas (re) a las cuales está obligado el colono a cumplir (cui colonum obligauerit) por derecho del propietario (iuris sui). Dentro de estas prerrogativas que el dueño no debería ejercer se encuentran el cumplimiento estricto de las fechas de pago (diebus pecuniarum), el pedido de leña (lignis) y demás "pequeñas cosas accesorias" (ceteris paruis accessionibus). Si estas "atenciones" que el colono debía prestar a su arrendador solían figurar en los contratos, es algo que no queda claro del texto de Columela. Pero que estos servicios no aparezcan en las disposiciones de los juristas nos puede más bien señalar que se trataba de costumbres que un contrato no regulaba. Caerían en este sentido bajo la misma rúbrica, por ejemplo, que los servicios militares que los colonos de Catilina y Domicio Enobarbo realizaban para sus patrones, como consta en los relatos de Salustio (Cat. 59) y Julio César (BC. I.34).

Luego advierte Columela acerca de la inconveniencia de ser del todo indulgente, ya que ello supondría el abandono de parte del colono de toda obligación hacia el dueño (I.7.2): "Nec rursus in totum remittendum, quoniam uel optima nomina non appellando fieri mala faenerator Alfius dixisse uerissime fertur" (Ed. Lündstrom, 1917: 37). Es significativo al respecto que Columela cite al faenerator Alfio sobre los peligros de la indolencia en el cobro de lo adeudado (uel optima nomina non apellando fieri mala). La equiparación de la 
renta (pensio, como así la había denominado) con una deuda (nomen), nos lleva a la delgada línea existente que debía haber entre un colono y un endeudado. Es la deuda del colono la que lo sujeta a las necesidades del dueño, y éste debía saber administrar bien este lazo, de forma tal que no sea "ofensiva" para el propio colono, pero que tampoco deje de ser rentable para el propietario.

Donde queda más patentemente clara la existencia de relación paternal y de confianza entre el colono y el propietario es en el consejo de Publio Volusio que Columela cita (I.7.3): "Sed et ipse nostra memoria ueterem consularem uirumque opulentissimum P. Volusium adseuerantem audiui felicissimum fundum esse, qui colonos indigenas haberet et tanquam in paterna possessione natos iam inde a cunabulis longa familiaritate retineret" (Ed. Lündstrom, ídem). De esta declaración se puede concluir con cierta certeza que una mera relación contractual no podía sostener por sí misma una relación social en el marco de una estructura agraria como la romana. Según Columela, Volusio aseguraba que el fundo más afortunado (felicissimum fundum) sería aquel que tuviera colonos nativos (colonos indigenas) y que los retuviera como si hubiesen nacido en la propiedad paterna (in paterna possessione natos), debido a una larga familiaridad desde la cuna (a cunabulis longa familiaritate). Por este motivo, Columela advierte sobre los peligros de alquilar repetidamente una heredad, ya que evitaría la construcción de este lazo personal (I.7.3): "Ita certe mea fert opinio rem malam esse frequentem locationem fundi, peiorem tamen urbanum colonum, qui per familiam mauult agrum quam per se colere" (Ed. Lündstrom, 1917: 37). Este apego a la tierra que Columela busca afianzar en el colono es lo que le hace desaconsejar recurrir a un colono de ciudad (urbanum colonum), ya que no trabaja la tierra él mismo sino que lo hace por medio de sus esclavos (per familiam mauult agrum quam per se colere). Podría concluirse de las aseveraciones anteriores de Columela que lo ideal sería la inexistencia misma de un contrato de arrendamiento. $\mathrm{Al}$ ser éste una fórmula jurídica que especifica los derechos de propiedad transferidos y sus términos, su ya sola enunciación debería ser algo ofensivo, pues regaría de desconfianza una relación que debía basarse en la familiaridad.

Lo aconsejado por Columela guarda bastante parecido con las recomendaciones que ya hiciera el viejo Catón en su De agri cultura (I.IV): "vicinis bonus esto; familiam ne siveris peccare. Si te libenter vicinitas videbit, facilius tua vendes, opera facilius locabis, operarios facilius conduces: si aedificabis, operis, iumentis, materie adiuvabunt: siquid bona salute usus venerit, benigne defendent" (Ed. Keil, 1884: 16). Catón aconseja al propietario ser un buen vecino (vicinis bonus esto), ya que si el vecindario lo ve con agrado (si te libenter vicinitas videbit), le será más fácil vender sus productos (facilius tua vendes), locar ciertos trabajos (opera facilius locabis) y contratar trabajadores (operarios facilius conduces). Para que este rudimentario mercado laboral funcionara, Catón advertía previamente que uno de los parámetros para comprar una propiedad debía ser la existencia de una abundante cantidad de trabajadores en las cercanías (I.I.3): "operarioum copia siet" (Ed. Keil, 1884: 12). En esto se observa posiblemente uno de los problemas que debían tener el funcionamiento de un mercado laboral en condiciones en las cuales no existía una plena movilidad de la fuerza de trabajo, sea por cuestiones técnicas y productivas (escaso desarrollo del transporte) como políticas o de estatus (inexistencia de un campesinado completamente desposeído, desprecio del trabajo asalariado como forma de esclavitud). Pero a esto se le suma que el lazo social que unía al empleador con el empleado o al locator con el conductor/colonus debía, por lo menos, aparecer como una relación cordial de intercambio de favores. El mismo Catón, usualmente señalado como el frío calculador utilitarista, representante del nuevo espíritu comercial que se apoderaba de la sociedad romana, recomendaba al propietario que en sus relaciones con el vecindario no mostrara precisamente estas cualidades, que las ocultara bajo el velo de las relaciones amistosas. Así, señala que los beneficios de ser un "buen vecino" redundan en la ayuda que el vecindario pueda dar al propietario en caso de que éste tuviera que edificar, con aportes en trabajo, animales o materiales ( $s i$ aedificabis, operis, iumentis, materiae adiuvabunt). Aún más, en caso de necesidad (siquid usus venerit), el vecindario lo ayudará de buena gana (benigne denfendent). 


\section{LA COMPATIBILIDAD ENTRE DEPENDENCIA Y RELACIÓN CONTRACTUAL}

Un hecho sobresaliente del análisis precedente es la naturaleza híbrida, a la vez contractual y personal, de las relaciones entre los sujetos que pueblan la campiña romana. Esta hibridez cuestiona una muy mentada clasificación teórica entre formas "económicas" de la propiedad, basadas en la libertad formal del contrato, y lo que autores como Meiksins Wood (2011: 62) denominaron "propiedad políticamente constituida”, caracterizada por relaciones de dominio y de servidumbre personal. ${ }^{3}$ La naturalización de esta división se ha asentado tan firmemente en la generación más reciente de historiadores del imperio romano que ya es un lugar común su clasificación entre aquellos que, a la hora de caracterizar el funcionamiento económico del imperio, privilegian en su explicación las market relations, "characterized by trade driven by comparative advantage", o quienes ponen el acento en las power relations, "such as tribute and rent-taking and slavery and their economic consequences" (Scheidel, 2012: 8). Puede decirse que la razón de ser de la Nueva Economía Institucional o de la Sociología Económica ha sido precisamente la de tratar de superar esta división, demostrando cómo los condicionantes sociales y culturales determinan la actividad económica, en tanto constituyen las "reglas de juego" que establecen los incentivos y restricciones a los agentes económicos (Scheidel, 2012: 9-10). Según el neoinstitucionalismo, los altos "costos de transacción" de las sociedades preindustriales, determinados por los costos de adquisición y diseminación de la información, del transporte y, muy importante para nosotros, del diseño y de los medios de hacer cumplir los contratos, suponían un escollo considerable para el funcionamiento de una economía de mercado plena. Ante esto, algunos adherentes de esta corriente señalaron que si bien es cierto que la sociedad moderna descansa sobre la tecnología para reducir estos costos y hacer funcionar una economía de mercado, los antiguos lo habrían hecho sobre la religión y la "buena voluntad": los juramentos sagrados y los rituales en la elaboración de los contratos, el énfasis en los estándares profesionales y en el mantenimiento de un buen nombre, la elevación y extensión de los lazos familiares y demás "departures from impersonality" lograrían demostrar entonces que una economía de mercado podía funcionar sin necesidad de la tecnología (Silver, 2004: 65).

Este tipo de reflexiones acerca de la impersonalidad del mundo moderno y sus diferencias con las sociedades pretéritas tiene ya una larga data. Georg Simmel (1977: 112) señalaba que en las sociedades más primitivas se sabía mucho más del asociado en lo personal, a la hora de formar una relación de confianza, que de las condiciones reales que posibilitarían una evaluación más objetiva, y podríamos citar también aquella corrección de Engels (1972: 80) a Henry Maine por haber creído descubrir que el pasaje de la sociedad antigua a la moderna fue from status to contract, algo que ya Marx había anunciado cuarenta años antes en el Manifiesto Comunista. El propio Maine (Godelier, 1976: 56) dejaba constancia de cómo los economistas de su época daban cuenta de las "fricciones" al normal funcionamiento del mercado que ocasionaban las extrañas costumbres que contaminaban las categorías económicas de propiedad, de renta, de ganancia y de competencia en las sociedades primitivas. Poco se avanza en el conocimiento de estas sociedades si ahora la evaluación se torna "positiva" y estas fricciones pasan a ser facilitadores del crecimiento económico en un mundo de elevados costos de transacción. La apelación a este abstracto criterio de eficiencia característico de la historiografía neoinstitucionalista ha tenido como consecuencia el olvido de los conflictos de clase en torno al control y a la subyugación del trabajo social. ${ }^{4}$ Es en este aspecto donde debemos fijar la mirada y tratar de comprender las relaciones laborales en un mundo cuyos elevados "costos de transacción" impedían o por lo menos modificaban radicalmente la forma en la cual se aseguraban los mecanismos de explotación de la fuerza laboral.

En este sentido, y a partir de lo analizado con anterioridad, podemos extraer la certeza de que los propietarios romanos no consideraban que fuese suficiente, ni siquiera tal vez deseable, que las relaciones entre el propietario y el vecindario, de donde se obtenía la mano de obra, se rigieran únicamente por medios contractuales. Los mecanismos impersonales de mercado resultaban insuficientes para mantener la estabilidad de la relación social, siendo necesarios apuntalamientos más "personales". La historiografía fue 
en general reacia a apreciar estos fenómenos. En base a la misma evidencia, Scheidel (1994: 56) se limitó a constatar, para el caso específico de Columela, no solo la existencia de un contrato voluntario cuya sola presencia descartaría de por sí cualquier forma de subordinación social, sino también la buena posición del colono/ farmer, ya que Columela recomendaba tratarlo con respeto. La visión de Scheidel corresponde a una extendida inclinación entre los romanistas a interpretar el derecho romano bajo la luz del derecho moderno, una concepción que creemos peca de cierta unilateralidad para comprender el contexto social en el cual se enmarca el derecho. Recuerda en cierto modo la actitud del legislador moderno denunciada por Marx en los debates en la Dieta Renana. Allí Marx (2007: 37) señalaba la unilateralidad del entendimiento moderno, incapaz de apreciar los derechos consuetudinarios de los pobres garantizados en aquella "mezcla de derecho privado y público que se nos presenta en todas las instituciones de la Edad Media". En su afán de eliminar cualquier forma híbrida y fluctuante de propiedad, las categorías del derecho moderno cortaron de cuajo estos aspectos "sentimentales" del feudalismo. Si bien es cierto que el derecho moderno heredó las categorías jurídicas del derecho romano, esto no implica que la concepción romana del contrato fuese igual a la actual. Cabe destacar en este sentido la postura de Alfons Bürge (1980: 106), quien señaló que las relaciones contractuales en Roma no buscaban corregir situaciones previas de desigualdad, sino que se apoyaban sobre estas mismas desigualdades preexistentes y las perpetuaban. Bürge notó precisamente el "apego sentimental del colono a la tierra" del que hablaba Columela como un componente esencial de sujeción de la mano de obra a las necesidades económicas de la explotación agrícola. Para que resultara efectiva, este tipo de dependencia no debía sentirse con demasiada dureza, con el objeto de mantener al colono al amparo de la influencia del dueño de la finca (Bürge, 1980: 147).

En este contexto, la relación contractual alimentaba la formación de una relación personal entre las partes. No se ha escapado a los ojos de la gran mayoría de los historiadores el carácter "draconiano" de los contratos de locación, como así también del tratamiento de los deudores (Finley, 1976: 114; Fustel de Coulanges, 1885: 18). El desbalance de poder entre las partes del contrato abría las puertas a un uso discrecional de las prerrogativas de parte del propietario: no había, por ejemplo, un procedimiento legal obligatorio que regulara la liquidación de los bienes del colono empeñados por la deuda, ni tampoco un proceso institucionalizado de reducción de las rentas debidas, cuestión que quedaba enteramente al arbitrio del dueño, a su gratia (Bürge, 1980: 146). Era precisamente esta combinación de extrema dureza y calculada ambigüedad de las disposiciones legales lo que abría la puerta a la configuración de lazos personales que terminaban atenuando los aspectos más draconianos de la ley. ${ }^{5}$ Claro está que si por un lado esto suponía un alivio para la situación de los colonos, por el otro lado anudaba de manera más firme que la propia ley el proceso de subordinación de los productores rurales. Aquellas abrumadoras demandas de los campesinos y colonos de Plinio, urgidos por sus estrecheces económicas, debían entonces de darle a éste una perfecta oportunidad para ejercer su gratia, afirmando así su capacidad de influencia sobre la comunidad rural.

\section{ESENCIA Y APARIENCIA DE LAS RELACIONES SOCIALES PRECAPITALISTAS}

$\mathrm{Si}$, como señalábamos, los aspectos contractuales y personales deben verse en una mutua interdependencia, es necesario también precisar cuáles son las determinaciones objetivas que ocasionan el cuadro descrito. Apreciamos en este sentido una coincidencia muy grande con lo que Pierre Bourdieu (2007: 180-1) denominó "una economía en sí y no para sí": una economía, propia de las sociedades precapitalistas, que no reconoce abiertamente los fines económicos lucrativos a los cuales está objetivamente orientada. El intercambio de dones resulta en este sentido un trabajo simbólico que apunta a transmutar, por la "sincera ficción” de un intercambio desinteresado, las relaciones inevitablemente interesadas que imponen, entre otros, la vecindad y el trabajo (Bourdieu, 2007: 179). Es así que toda esta labor invertida en disimular las relaciones de interés, sea mediante la entrega de regalos o la celebración de fiestas y banquetes, constituyen una parte no menor y esencial del trabajo que una sociedad invierte en su reproducción. Esta cuestión marcada por 
Bourdieu nos parece fundamental ya que nos permite concluir que las sociedades basadas en el predominio de las relaciones personales no suelen ser más "diáfanas" que aquellas basadas en la impersonalidad de las relaciones mercantiles. A pesar de aquella conocida alusión de Marx (2002: 93) a la "transparencia" de las relaciones sociales precapitalistas, en oposición al velo que la forma dinero tiende a expandir sobre el carácter social de los trabajos privados, se puede afirmar que si bien aquello que está oculto en la sociedad capitalista (las relaciones entre personas) se observa claramente en las sociedades que la antecedieron, no menos cierto es que en estas últimas "lo económico no es directamente visible con claridad" (Althusser, 2006: 193).

Nótese que esto no equivale en absoluto a la interpretación de ciertas corrientes de la antropología que "festejan" a las sociedades primitivas por ser "sociedades de rechazo a la economía", como se lee en autores como Pierre Clastres (1981: 142). Al considerar que las relaciones de reciprocidad y de obligación revisten valores morales enteramente "extra-económicos", estas posturas supuestamente extremistas caen en la mayor mistificación posible de la economía capitalista de mercado, considerada ya como la única economía propiamente dicha (Lojkine, 1989: 142-3). Creer que, por el hecho de que "el hombre primitivo no esté, como el capitalista, animado por el gusto del beneficio", la sociedad primitiva sea "una sociedad sin economía" o incluso "una sociedad contra la economía" (Clastres, 1981: 142) no es más que caer en aquellos "archiconocidos lugares comunes" de afirmar que ni en la Antigüedad ni en la Edad Media predominaba la economía, sino la política en una y la religión en la otra, como Marx se encargaba de responder a una reseña crítica de El Capital: "Lo indiscutible es que ni la Edad Media pudo vivir de catolicismo ni el mundo antiguo de política. Es, a la inversa, el modo y manera en que la primera y el segundo se ganaban la vida, lo que explica por qué en un caso la política y en otro el catolicismo desempeñaron el papel protagónico" (Marx, 2002: 100). En este sentido, la pregunta a formularse es por qué las relaciones económicas entre colonos y propietarios adquirían la forma de una relación moral y paternalista o, para retomar las categorías con las cuales comenzábamos el análisis, por qué estas relaciones económicas aparecen como relaciones sentimentales.

Como hemos visto, estos lazos personales se expresaban mediante la entrega de regalos; no adquirían la forma de un intercambio de mercancías. Los presentes constituían una obligación ya que el objeto que se recibe, apelando a la clásica definición de Mauss (2012: 88), no era algo inerte sino que tenía un valor simbólico, entablaba una serie de obligaciones entre las partes. Mauss (2012: 203) también señalaba que fueron los griegos y los romanos quienes mediante el desarrollo del derecho contractual y su separación de cualquier obligación moral "superaron toda esa moralidad envejecida y esa economía del don demasiado azarosa, demasiado dispendiosa y demasiado suntuaria, repleta de consideraciones personales, incompatible con el desarrollo del mercado, del comercio y la producción". Por lo anteriormente analizado, cabe dudar de si realmente pudieron superar del todo esa "moralidad envejecida". En ocasiones se acepta con demasiada facilidad la idea de que la incorporación del campesinado a la comunidad política le liberaba de por sí de cualquier subordinación político-jurídica. Afirmaciones del siguiente tenor, como la formulada por Meiksins Wood (2011:156) para el imperio romano, de que "puesto que la ciudadanía de los campesinos excluía su dependencia jurídica, su explotación -como arrendatarios o labriegos ocasionales- dependía de su vulnerabilidad económica", le da a nuestro entender demasiado crédito a la capacidad de la clase terrateniente romana de poder explotar solo por medios económicos a grandes sectores del campesinado. Si realmente fuese así, ¿por qué necesitaban que el colono sintiera una conexión sentimental con la tierra? ¿Por qué el propietario debía ser un padre para él? ¿Por qué, en definitiva, se necesitaba una pátina de Gemeinschaft para que esa Gesellschaft disfrazada, cuya base en el fondo era utilitaria, pudiera funcionar? (Cohen, 1986: 366).

Ante todo debemos deshacernos de cierto malentendido con el cual nos hemos manejado hasta aquí. Pareciera que bastara con correrle el velo a estos sujetos cautivos por la ilusión de las relaciones personales para hacerles ver la verdadera esencia de la realidad. Pero con esta ingenua presunción solo afectaríamos conciencias individuales, pero las condiciones materiales que precisamente generan este tipo de ilusiones permanecerían inalteradas. La ideología, en tanto que "representa la relación imaginaria de los individuos 
con sus condiciones reales de existencia" (Althusser, 1974: 54), no es algo enteramente falso. La falsedad consiste en tomar cierta representación imaginaria de los sujetos, que por sí sola constituye un aspecto parcial de la realidad, por representación genuina de todas las determinaciones de la realidad. No se deja de ver un espejismo por más que uno pueda explicar sus causas. En este sentido, podemos afirmar que la apariencia ya es la esencia que se manifiesta. Si hasta aquí apelamos a una noción más bien kantiana, de apariencia como contraste contra una esencia supuestamente oculta o trascendental, se trata más bien de apelar a la noción hegeliana de una esencia que no permanece detrás de la apariencia, sino como apareciendo de la necesidad interna, "como desplegada respecto a manifestar una necesidad que es determinada por la naturaleza al llegar a ser totalmente manifiesta" (Taylor, 2010: 235).

A partir de aquí podemos retomar nuevamente el análisis de Marx sobre la "concepción aristocrática de la propiedad" de la que nos servíamos para caracterizar el comportamiento de Plinio o del ficticio Melibeo. Si bien en algunos pasajes de su obra Marx considera que las relaciones sociales de las sociedades anteriores al capitalismo eran "transparentes", en otros pasajes dejó entrever una noción distinta. Así, en los Grundrisse, Marx (1982: 92-93) advertía lo siguiente:

\footnotetext{
“(Frente a la ilusión de las 'relaciones puramente personales' de la edad feudal, etc., no debe naturalmente olvidarse ni siquiera por un instante que 1) estas mismas relaciones, en una fase determinada, revistieron en el interior de su esfera un carácter material, como lo demuestran por ejemplo el desarrollo de las relaciones de propiedad de la tierra a partir de las relaciones de subordinación puramente militares; 2) la relación material que las cancela tiene ella misma un carácter limitado, un carácter determinado por la naturaleza, y por ello aparece como relación personal, mientras que en el mundo moderno las relaciones personales se muestran como una simple emanación de las relaciones de producción y de cambio.)”
}

¿En qué consiste entonces el carácter limitado de la relación material, y su consecuente forma de manifestación sobre la conciencia de los agentes bajo la apariencia de acogedoras relaciones personales? Creemos que este fenómeno se debe a la ausencia en las relaciones laborales de la estabilidad necesaria para mantenerse por medios estrictamente objetivos. Un proceso de internalización de la mano de obra, como veíamos en el consejo de Columela de retener a los colonos "como si hubieran nacido en la casa paterna", suponía una ventaja para el propietario al permitirle desentenderse de la necesidad de acudir a un mercado de trabajo frágil y discontinuo (Colombo y Ríos, en este dossier). No debe olvidarse ante todo que estamos ante formas de mediación social que son inmanentes a distintos modos de producción. Todo el trabajo invertido en la manutención de la relación entre el propietario y el colono que hemos visto, como el intercambio de regalos, las atenciones, los saludos, las prestaciones de favores, etc., tanto en una como en otra dirección, solo formalmente se diferencian de otras formas menos directas de la subyugación laboral, pero más implacables, como la relación asalariada moderna. Ésta "encubre, como mera relación monetaria, la transacción real y la dependencia perpetua que esa intermediación de la compraventa renueva incesantemente” (Marx, 1971: 105).

Nos enfrentamos aquí a una interesante paradoja. Si en el capitalismo moderno la compraventa constante en el mercado de la mercancía fuerza de trabajo le confiere a esta relación de dependencia "la apariencia falaz de una transacción, de un contrato entre poseedores de mercancías dotados de iguales derechos y que se contraponen de manera igualmente libre" (Marx, 1971: 105), habría que pensar si no sería precisamente el contrato antiguo una forma quizá más genuina de transacción entre voluntades libres. El gran espacio que el derecho romano abría a la arbitrariedad del propietario podía ser naturalmente aprovechada por aquel pero también por la parte más débil, el colono, quien ante una hipotética negativa del dueño a condonar un retraso en la renta podría tratar de buscarse una contraparte más comprensiva y "paternal", alguien de "tiernas cejas, pero más tierno el corazón que el rostro".

\section{Bibliografía}

Baehrens, E. (1881). Poetae Latini Minores. III. Teubner: Leipzig. 
Friedlander, L. (1886). M. Valerii Martialis epigrammaton libri. Teubner: Leipzig.

Keil, H. (1884). M. Porci Catonis De Agri Cultura liber. M. Terenti Varronis Rerum Rusticarum libri tres. Teubner: Leipzig.

Keil, H. (1886). C. Plini Caecili Secundi Epistularum libri novem Epistularum ad Traianum Panegyricus. Teubner: Leipzig.

Lündstrom, V. (1917). L. Iunii Moderati Columellae opera quae exstant. Teubner: Upsala.

Althusser, L. (2006). Para leer El Capital. Buenos Aires: Siglo XXI.

Althusser, L. (1974). Ideología y aparatos ideológicos de Estado. Buenos Aires: Nueva Visión.

Bourdieu, P. (2007). El sentido práctico. Buenos Aires: Siglo XXI.

Brunt, P. A., (1962). "The Army and the Land in the Roman Revolution". The Journal of Roman Studies, 52, 69-86.

Bürge, A. (1980). "Vertrag und personale Abhängigkeiten im Rom der späten Republik un der frühen Kaiserzeit". Zeitschrift der Savigny-Stiftung für Rechtsgeschichte. Romanistische Abteilung, 97, 105-156. Disponible en: http: //libgen.io/scimag/journaltable.php?journalid=27284

Clastres, P. (1981). Investigaciones en antropología politica. Barcelona: Gedisa.

Cohen, G. (1986). La teoría de la historia de Karl Marx. Una defensa. Madrid: Siglo XXI.

Engels, F. (1972). El origen de la familia, de la propiedad privada y del estado. Madrid: Ayuso.

Finley, M. I. (1976). Private Farm Tenancy in Italy before Diocletian. En M. I. Finley (Ed.), Studies in Roman Property. Cambridge: Cambridge University Press.

Fustel de Coulanges, N. D. (1885). Recherches sur quelques problèmes d' histoire. París: Hachette.

Godelier, M. (Ed.) (1976). Antropologia y Economia. Textos de Marx, Maine, Morgan, etc. Barcelona: Anagrama.

Johne, K. P., Köhn, J., y Weber, V. (1983). Die Kolonen in Italien und den westlichen Provinzen des römischen Reiches. Eine Untersuchung der literarischen, juristischen und epigraphischen Quellen vom 2. Jabrhundert v. u. Z. bis zu den Severen. Berlín: Akademie-Verlag.

Kolendo, J. (1976). Le colonat en Afrique sous le Haut-Empire. París: Les Belles Lettres.

Lojkine, J. (1989). "Mauss et l' «Essai sur le don». Portée contemporaine d'une étude anthropologique sur une économie non marchande". Cahiers Internationaux de Sociologie, 86, 141-158.

Marx, K. (1971). El Capital Libro I Capitulo VI (inédito). Resultados del proceso inmediato deproducción. Buenos Aires: Siglo XXI.

Marx, K. (1982). Elementos fundamentales para la crítica de la economía politica (Grundrisse) 1857-1858. Buenos Aires: Siglo XXI.

Marx, K. (2002). El Capital I, vol. 1. Buenos Aires: Siglo XXI.

Marx, K. (2004). Manuscritos económico-filosóficos de 1844. Buenos Aires: Colihue.

Marx, K. (2007). Los debates de la Dieta Renana. Buenos Aires: Gedisa.

Mauss, M. (2012). Ensayo sobre el don. Forma y Función del intercambio en las sociedades arcaicas. Buenos Aires: Katz.

Meiksins Wood, E. (2011). De ciudadanos a señoresfeudales. Historia social delpensamientopolitico desde la Antigüedad a la Edad Media. Madrid: Paidós.

Sahlins, M. (1977). Economia de la Edad de Piedra. Madrid: Akal.

Scheidel, W. (1994). Grundpacht und Lohnarbeit in der Landwirtschaft des römischen Italien. Frankfurt am Main: Peter Lang.

Scheidel, W. (2012). Approaching the Roman Economy. En W. Scheidel (Ed.), The Cambridge Companion to the Roman Economy (pp. 1-21). Cambridge: Cambridge University Press.

Schtajerman, E. M. (1964). Die Krise der Sklavenhalterordnung im Westen des Römischen Reiches. Berlín: AkademieVerlag.

Schultz, C. L. F. (1833). Grundlegung zu einer geschichtlichen Staatswissenschaft der Römer. Colonia: J. P. Bachem. 
Silver, M. (2004). Modern Ancients. En Rollinger, R., Schnegg, K. y Ulf, C. (Eds.), Commerce and Monetary Systems in the Ancient World: Means of Transmission and Cultural Interaction (pp. 65-87). Stuttgart: Steiner.

Simmel, G. (1977). Sociología. Estudios sobre las formas de socialización. Madrid: Revista de Occidente.

Taylor, Ch. (2010). Hegel. Barcelona: Anthropos.

Weber, M. (1982). Historia agraria romana. Madrid: Akal.

\section{Notas}

1 En los códices se lee patiens, "pacientemente" (Ed. Baehrens, 1881: 178).

2 Téngase en cuenta la polisemia de la palabra colonus, que puede significar tanto "campesino" como "arrendatario", siendo difícil a veces dilucidar el significado exacto que el autor en cuestión le adjudica.

3 Véase la crítica a esta dicotomía de Colombo, en este dossier.

4 Véase el artículo de Fazzini, en este dossier.

5 "Andererseits dürfte die schlechte Rechtsstellung des Mieters, Verpächters, Lohnarbeiters und Prekaristen, um nur das wichtigste zu nennen, durch die Möglichkeiten, die eine personale Beziehung bietet, oft gemildert worden sein (Bürge, 1980: 153)."

\section{BY-NC-SA}

